Research Article

\title{
Acid Hydrolysis of Bis(2,2'; 6',2"-Terpyridyl) Iron(II) Complex in the Water Pools of CTAB/Hexane/Chloroform Reverse Micelles-A Kinetic Study in Confined Medium
}

\author{
K.V. Nagalakshmi ${ }^{1}$, P. Shyamala ${ }^{2 *}$ \\ ${ }^{1}$ Department of Chemistry, Gayatri Vidya Parishad College of Engineering (Autonomous), \\ Madhurawada, Visakhapatnam-530048, Andhra Pradesh, India. \\ ${ }^{2}$ Department of PNCO, School of Chemistry, Andhra University, Visakhapatnam-530017, Andhra
}

Pradesh, India.

Received: $6^{\text {th }}$ July 2020; Revised: $1^{\text {st }}$ December 2020; Accepted: $2^{\text {nd }}$ December 2020; Available online: 19 th December 2020; Published regularly: December 2020

\begin{abstract}
The kinetics of acid hydrolysis of bis(2,2';6', 2"-terpyridyl) iron(II) complex has been studied in $\mathrm{CTAB} /$ Hexane/Chloroform reverse micelles. The reaction obeys first order kinetics with respect to each of the reactants at all values of $W,\left\{W=\left[\mathrm{H}_{2} \mathrm{O}\right] /[\mathrm{CTAB}]\right\}$. In the reverse micellar medium, the reaction is much slower compared to aqueous medium due to low micropolarity of the water pools which does not facilitate a reaction between reactants of same charge. The effect of variation of $W\left\{W=\left[\mathrm{H}_{2} \mathrm{O}\right] /[\mathrm{CTAB}]\right\}$ at constant $[\mathrm{CTAB}]$ and variation of $[\mathrm{CTAB}]$ at fixed $W$ has been studied. The second order rate constant $\left(k_{2}\right)$ of the reaction increases as the value of $W$ increases up to $W=8.88$ and remains constant thereafter and it is independent of concentration of [CTAB] at constant $W$. The variation of rate of reaction with $W$ has been explained by considering variation of micropolarity and ionic strength of water pools of reverse micelles with $W$. Copyright $\odot 2020$ BCREC Group. All rights reserved
\end{abstract}

Keywords: Kinetics; Acid hydrolysis; Bis $\left(2,2^{\prime}: 6^{\prime}, 2^{\prime \prime}\right.$-terpyridine) iron (II); Reverse micelles; Water pools

How to Cite: Nagalakshmi, K.V., Shyamala, P. (2020). Acid Hydrolysis of Bis(2,2'; 6',2"-Terpyridyl) Iron(II) Complex in the Water Pools of CTAB/Hexane/Chloroform Reverse Micelles-A Kinetic Study in Confined Medium. Bulletin of Chemical Reaction Engineering \& Catalysis, 15(3), 853-860 (doi:10.9767/bcrec.15.3.8425.853-860)

Permalink/DOI: https://doi.org/10.9767/bcrec.15.3.8425.853-860

\section{Introduction}

The reverse micelles formed spontaneously in organic solvents are thermodynamically stable and have been characterized by various techniques [1-3]. The solubilized water present in the polar cavity of reverse micelles is called "water pool". This water pool has unique proper-

* Corresponding Author.

Email: shyamalapulipaka@rediffmail.com

(Shyamala. P.) ties like low dielectric constant, i.e. micropolarity, higher viscosity, low thermodynamic activity of water, higher ionic strength (in the case of reverse micelles made of ionic surfactants) and altered nucleophilicity compared to water in the conventional aqueous media [4-6]. These special properties of the water pool are dependent on a $W$ parameter, $W=\left(\left[\mathrm{H}_{2} \mathrm{O}\right] /[\right.$ Surfactant $\left.]\right)$ and as the value of $W$ increases the properties approach that of ordinary water $[7,8]$. In addition to these properties, when reactants are in the water pool they are confined to a small volume 
leading to a concentration effect. The water pool is therefore referred to as a micro reactor [9]. Therefore, this media is very useful for the synthesis of nanoparticles with desired shape and size [10-12]. Since the water pool has different properties compared to ordinary water the rates of reactions and mechanisms can be expected to be different [13-16]. Another advantage of reverse micelles is that they are good solvents for both hydrophobic and hydrophilic reactants and therefore, appear to be useful media for studying reactions involving different types of reactants [17-19].

Studies on the kinetics of electron transfer reactions in the presence of CTAB/Hexane/Chloroform reverse micelles are very few. The kinetics of dissociation of $\left[\mathrm{Fe}(\mathrm{bpy})_{3}\right]^{2+},\left[\mathrm{Fe}(\mathrm{tptz})_{2}\right]^{2+},\left[\mathrm{Fe}(\text { phen })_{3}\right]^{2+}$ in the presence of CTAB reverse micelles have been earlier reported and found that low dielectric constant of the water pool facilitates the formation of ion pair between complex and bromide ion of CTAB and leads to increase in rate [20-22]. In the study of kinetics of oxidation of $\left[\mathrm{Fe}(\text { phen })_{3}\right]^{2+}$ in CTAB reverse micelles, quantitative assessment for the change in special properties with change in $\mathrm{W}$ has been given and the observed kinetic results has been quantitatively explained using Guggenheim equation [23].

In order to further investigate the influence of these unique properties on the kinetics of hydrolysis reactions, we have taken up a study of the acid hydrolysis of $\left[\mathrm{Fe}(\text { tpy })_{2}\right]^{2+}$ in the presence of CTAB/Hexane/Chloroform reverse micelles.

\section{Materials and Methods}

\subsection{Materials}

All solutions were prepared in double distilled water. Chemicals used were of analytical grade. 0.02 mol. $\mathrm{dm}^{-3}$ bis $\left(2,2^{\prime} ; 6^{\prime}, 2^{\prime \prime}\right.$-terpyridyl) iron(II) complex was prepared by mixing stoichiometric amounts (1:2) of ferrous ammonium sulphate (99\% pure, Merck, India) and terpyridine (99\% pure, Sigma Aldrich, India) in water. Stock solution of sulphuric acid (Merck, India) was freshly prepared and standardized.

Chloroform (Merck, India) and hexane (Merck, India) were double distilled before use. CTAB (Cetyl trimethyl ammonium bromide) purchased from Sigma (98\% pure) was used without further purification. Stock solution of $0.1 \mathrm{M}$ CTAB reverse micellar solution in 100 $\mathrm{mL}$ was prepared by mixing $3.64 \mathrm{~g}$ CTAB, 40 $\mathrm{mL}$ hexane, $60 \mathrm{~mL}$ chloroform till a clear solution was obtained. 0.2 mol. $\mathrm{dm}^{-3}$ and 0.3 mol.dm ${ }^{-3}$ CTAB reverse micellar solutions were also prepared by dissolving requisite amounts of CTAB in chloroform-hexane $(3: 2 \mathrm{v} / \mathrm{v})$ mixtures. The solutions were used within $24 \mathrm{~h}$ of preparation.

\subsection{Preparation of Reverse Micellar Medium and Initiation of the Reaction}

The $0.02 \mathrm{~mL}$ of $\left[\mathrm{Fe}\left(\mathrm{tpy}_{2}\right)_{2}\right]^{2+}$ of concentration $0.02 \mathrm{~mol} . \mathrm{dm}^{-3}$ was injected into $10 \mathrm{~mL}$ of 0.1 mol. $\mathrm{dm}^{-3} \mathrm{CTAB}$ solution using a micro pipette. $0.02 \mathrm{~mL}$ of acid solution (11.0 mol. $\left.\mathrm{dm}^{-3}\right)$ was then added to initiate the reaction. The reaction mixtures were shaken vigorously to obtain a transparent and homogenous solution that can be regarded as a reverse micellar system. The molar ratio of [Water] to [CTAB], i.e. $W$ was varied in the range 2.22 to 16.6 by adding requisite amount of water.

2.3 Experimental Method of Following the Reaction

The kinetic study of the acid hydrolysis of $\left[\mathrm{Fe}(\text { tpy })_{2}\right]^{2+}$ was carried out using a Shimadzu UV-1800 double beam spectrophotometer by measuring the decrease in absorbance of $\left[\mathrm{Fe}(\text { tpy })_{2}\right]^{2+}$ at a wave length at $556 \mathrm{~nm}$ against blank 3:2 mixture of chloroform and hexane. The reaction was carried out under the pseudo first order conditions, $\left.\left[\mathrm{H}^{+}\right]>>\left[\mathrm{Fe}(\text { tpy })_{2}\right]^{2+}\right]$. The concentration of $\left[\mathrm{Fe}(\text { tpy })_{2}\right]^{2+}$ was $4 \times 10^{-5}$ mol. $\mathrm{dm}^{-3}$, acid were varied from $2.22 \times 10^{-2}$ to $18.5 \times 10^{-2} \mathrm{~mol}_{\mathrm{dm}} \mathrm{dm}^{-3}$. In all cases good linear plots were obtained for log (absorbance) versus time indicating first order kinetics with respect to $\left[\mathrm{Fe}(\text { tpy })_{2}\right]^{2+}$. The kinetic data are the averages from duplicate runs with reproducibility less than $\pm 3 \%$.

\subsection{Product Analysis and Stoichiometry}

The solution of $4.0 \times 10^{-5}$ mol. $\mathrm{dm}^{-3}$ $\left\{\mathrm{Fe}(\text { tpy })_{2}\right\}^{2+}$ was added to $0.1 \mathrm{~mol} . \mathrm{dm}^{-3} \mathrm{CTAB}$ reverse micellar solution in presence of excess sulphuric acid. After the completion of reaction, UV-Visible spectrum of the product was compared with terpydine of same concentration. In the visible region, there was no absorbance at $556 \mathrm{~nm}$ corresponding to the $\left\{\mathrm{Fe}(\text { tpy })_{2}\right\}^{2+}$ complex indicating the dissociation of the complex to free metal ion and ligand. No red colour was obtained on the addition of ammonium thiocyanate indicating the absence of $\mathrm{Fe}$ (III) and deep blue color was observed on addition of few drops of $\mathrm{K}_{3}[\mathrm{Fe}(\mathrm{CN})]_{6}$ the indicating the presence of $\mathrm{Fe}^{2+}$. 
The stoichiometry for the reaction between $\left[\mathrm{Fe}(\text { tpy })_{2}\right]^{+2}$ and $\mathrm{H}^{+}$determined by spectrophotometry using mole ratio method, keeping the concentration of the $\left[\mathrm{Fe}(\text { tpy })_{2}\right]^{+2}$, constant at $4 \times 10^{-5} \mathrm{~mol} . \mathrm{dm}^{-3}$ and varying the concentrations of $\mathrm{H}^{+}$in the presence of $0.1 \mathrm{~mol} . \mathrm{dm}^{-3}$ CTAB reverse micellar medium at $W=6.66$. The absorbance of the reaction product was measured at $\lambda_{\max }=556 \mathrm{~nm}, \mathrm{~T}=304 \pm 0.1 \mathrm{~K}$ after a fixed time interval of 24 hours. The mole ratio corresponds to the intersection point from the plot of absorbance versus mole ratio $\left(\left[\mathrm{H}^{+}\right] /\left[\left[\mathrm{Fe}\left(\mathrm{tpy}_{2}\right]_{2}\right]^{+}\right]\right)$(Figure 1) and it indicates that one mole of $\left[\mathrm{Fe}(\text { tpy })_{2}\right]^{+}$reacts with two moles of $\mathrm{H}^{+}$.

\subsection{Calculation of Effective Concentration}

When reactants are in the water pool, they are confined to a small volume leading to a concentration effect. In the case of unimolecular reactions taking place in the water pools of reverse micelles, the measured first order rate constants can be compared directly with the rate constant of reaction in aqueous medium.

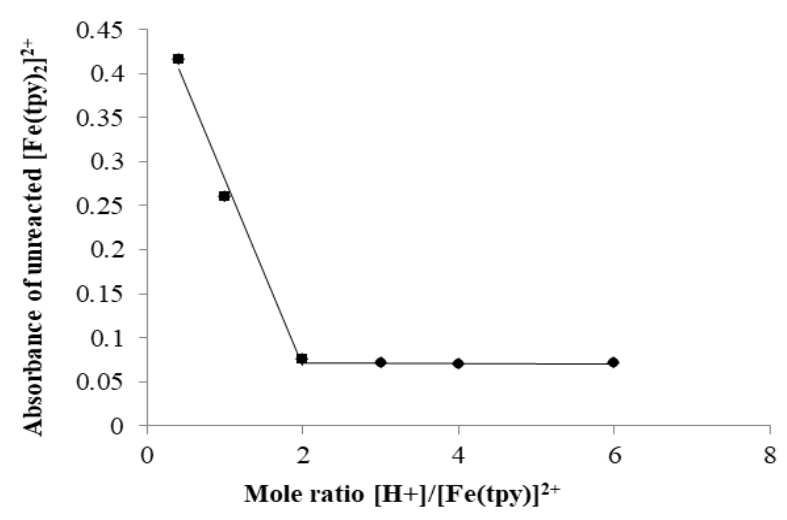

Figure 1. Plots of $\left[\mathrm{H}^{+}\right] /[\mathrm{Fe}(\text { tpy })]^{2+}$ vs Absorbance of unreacted $\left[\mathrm{Fe}(\text { tpy })^{2+}\right.$.

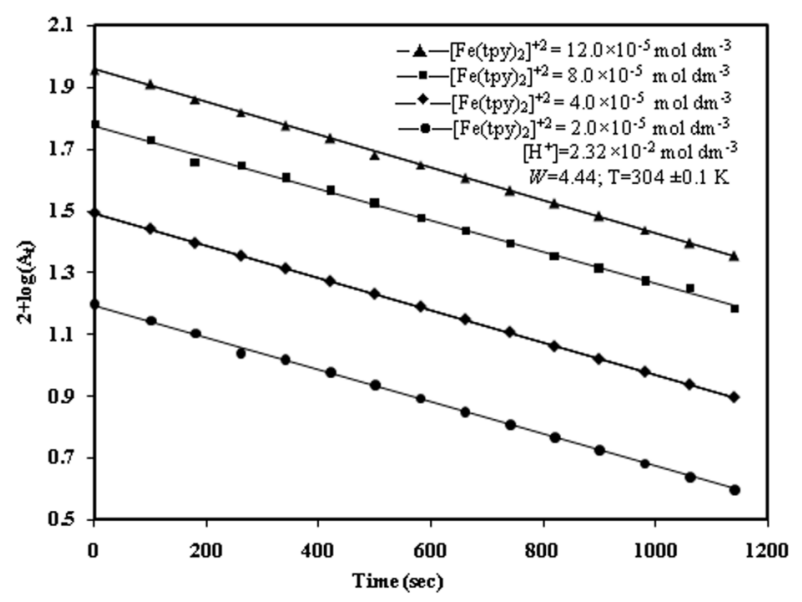

Figure 2. Plots of $\log \left(A_{\mathrm{t}}\right)$ versus time.
However, in the case of bimolecular reactions taking place in the water pools of the reverse micelles, the calculation of second order rate constant involves the consideration of effective concentration of the reactants. The effective concentration of a reactant in the water pool is calculated by dividing the overall concentration by the volume fraction of solubilised water. Volume fraction, $f$ is volume of aqueous phase in water pool divided by total volume of the solution [24]. The volume fractions lie in the range 4.00 to $25.2 \times 10^{-3}$ for $0.1 \mathrm{~mol} . \mathrm{dm}^{-3} \mathrm{CTAB}$. For example, if the concentration of CTAB is $0.1 \mathrm{~mol} . \mathrm{dm}^{-3}$ and $W=3.33$ then $f=(0.06 / 10.0)$.

If $\left[\mathrm{H}^{+}\right]_{\text {overall }}=2.0 \times 10^{-3}$ then $\left[\mathrm{H}^{+}\right]_{\text {effective }}=$ $\left\{\left[\mathrm{H}^{+}\right]_{\text {overall }} / f\right\}=\left\{2.0 \times 10^{-3} / 0.006\right\}=0.33 \mathrm{~mol} . \mathrm{dm}^{-3}$. From now onwards, the subscript 'o' is used to represent overall concentration and subscript 'e' to represent effective concentrations.

\subsection{Effect of Bromide Ion Concentration}

As CTAB has large concentration of bromide ion, it is necessary to check the nucleophilic effect of bromide ion on the reaction. To test whether the change in concentration of bromide affects reaction rate, kinetic runs were carried out in the presence of added bromide at constant concentrations of CTAB, complex and sulphuric acid which corresponds to effective concentration range of 3.33 to 13.00 . The total concentration of bromide ion in the water pool is obtained by dividing the overall concentration of added $\mathrm{Br}$ - by the volume fraction of dissolved water and adding this quantity to the effective concentration of bromide ion from CTAB. There is no increase in reaction rate with increase in bromide ion concentration (Table 1).

\section{Results and Discussion}

The kinetics of aquation of $\left\{\mathrm{Fe}(\mathrm{tpy})_{2}\right\}^{2+}$ in the presence of acid has been studied in the presence of CTAB reverse micelles. The reaction obeys simple first order kinetics with respect to

Table 1. Effect of variation of [Br-].

\begin{tabular}{ccc}
\hline $\begin{array}{c}\text { Added }[\mathrm{Br}-] \\
\left(\mathrm{mol.dm}^{-3}\right)\end{array}$ & $\begin{array}{c}{[\mathrm{Br}-]_{\mathrm{e}}} \\
\left(\mathrm{mol}_{\mathrm{dm}}{ }^{-3}\right)\end{array}$ & $\begin{array}{c}k^{\prime} \times 10^{3} \\
\left(\mathrm{sec}^{-1}\right)\end{array}$ \\
\hline 0.1 & 3.33 & 0.82 \\
0.16 & 5.33 & 0.83 \\
0.39 & 13.00 & 0.83 \\
\hline
\end{tabular}

$\left[\mathrm{Fe}(\text { tpy })_{2}\right]_{\mathrm{o}^{2+}}=4.0 \times 10^{-5} \mathrm{~mol} . \mathrm{dm}^{-3} ;\left[\mathrm{H}^{+}\right]_{\mathrm{o}}=2.0 \times 10^{-2} \mathrm{~mol} \mathrm{dm}^{-3} ;$ $[\mathrm{CTAB}]=0.1 \mathrm{~mol} . \mathrm{dm}^{-3} ; W=16.6 ; \mathrm{T}=304 \pm 0.1 \mathrm{~K}$ 
$\left\{\mathrm{Fe}(\mathrm{tpy})_{2}\right\}^{2+}$ as shown by linear plots of log (absorbance) versus time for at least $98 \%$ of the reaction under the conditions, $\left[\mathrm{Fe}(\text { tpy })_{2}\right]^{2+}<<$ $\left[\mathrm{H}^{+}\right]$(Figure 2). Since there is no deviation from linearity, there is no auto inhibitory effect of the product, terpyridine on the reaction. This is because of the high solubility of this ligand in the organic phase compared to water and the transfer of dissociated ligand occurring very

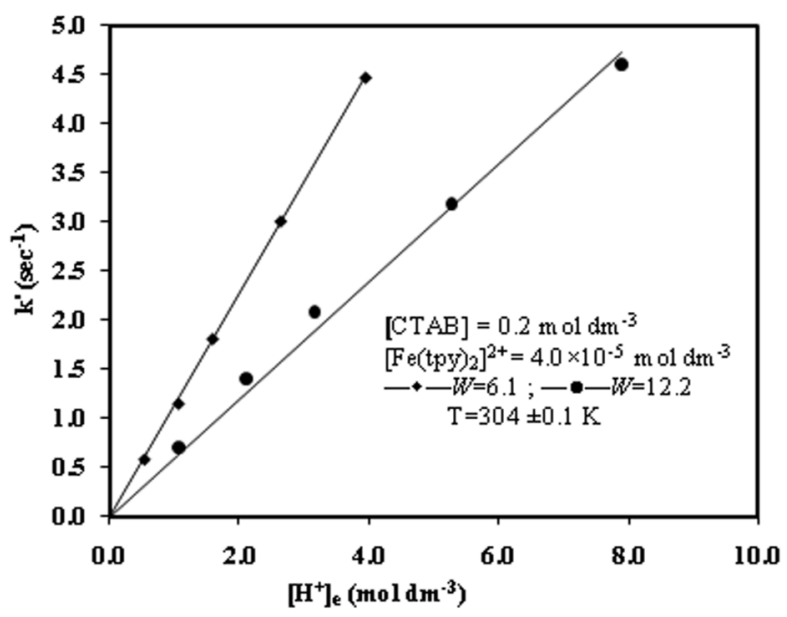

Figure 3. Plots of $k^{\prime}$ versus $\left[\mathrm{H}^{+}\right]_{\mathrm{e}}$ fast. A plot of pseudo first order rate constant, $k^{\prime}$ versus $\left[\mathrm{H}^{+}\right]$was found to be linear passing through the origin indicating first order kinetics with respect to $\mathrm{H}^{+}$(Figure 3).

The dissociation of $\left\{\mathrm{Fe}(\mathrm{tpy})_{2}\right\}^{2+}$ in the absence of acid in CTAB reverse micelles was found to be immeasurably slow although ion pair formation between the complex and $\mathrm{Br}$ - is favourable under low dielectric conditions. This is because of the high stability constant of the complex (Scheme 1). But equations of $\left\{\mathrm{Fe}(\mathrm{tpy})_{2}\right\}^{2+}$ has been observed in the presence of acid in CTAB reverse micelles and the reaction proceeds with a rate constant $k^{\prime}=2.89 \times 10^{-3}$ $\sec ^{-1}\left(\right.$ at $\left[\mathrm{Fe}(\text { tpy })_{2}\right]^{2+}=4.0 \times 10^{-5} \mathrm{~mol} . \mathrm{dm}^{-3} ;\left[\mathrm{H}^{+}\right]=$ $2.22 \times 10^{-2}$ mol.dm $\left.{ }^{-3} ; W=4.44\right)$.

To compare the rate of the reaction in reverse micelles and in aqueous medium, the kinetic runs were carried out keeping the overall concentration of reactants and ionic strength same in both the media. The value of ionic strength inside the droplets is obtained by dividing the overall counter ion concentration (which is equal to the stoichiometric surfactant concentration) by the volume fraction [25]. It can be seen that at same ionic strength and re-

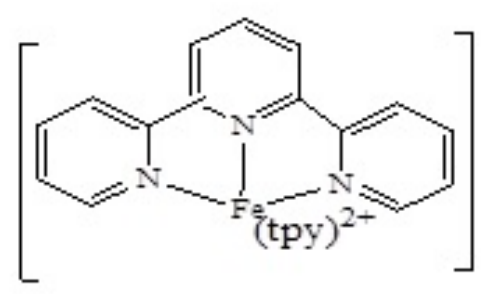

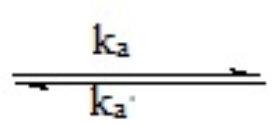

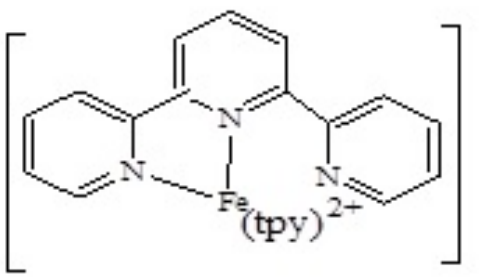<smiles>[Mg][Mg][TlH]</smiles>

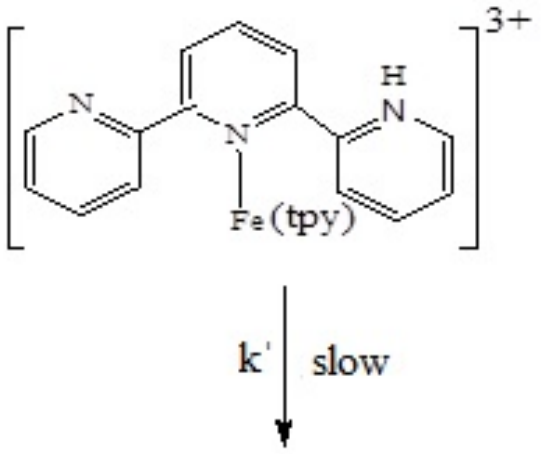<smiles>C1=CCCCC1</smiles>

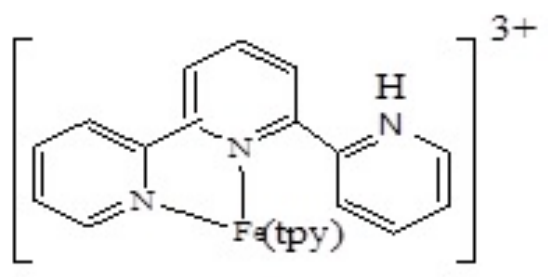

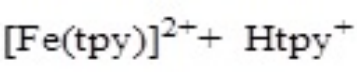

fast

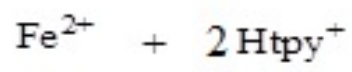

Scheme 1. Mechanism of the reaction 
Table 2. Comparison of rate constants in the aqueous medium and in the presence of $0.1 \mathrm{~mol}^{-\mathrm{dm}^{-3}}$ $\mathrm{CTAB}$ at same ionic strength.

\begin{tabular}{ccccc}
\hline $\begin{array}{c}{[\mathrm{Br}-]} \\
\left(\mathrm{mol} \mathrm{dm}^{-3}\right)\end{array}$ & $\begin{array}{c}k_{\text {aq.med }}^{\prime} \times 10^{3} \\
\left(\mathrm{sec}^{-1}\right)\end{array}$ & $\begin{array}{c}k_{2 \text { (aq.med) }} \times 10^{3} \\
\left(\mathrm{dm}^{3} \cdot \mathrm{mol}^{-1} \cdot \mathrm{sec}^{-1}\right)\end{array}$ & $\begin{array}{c}k^{\prime}(\text { rev mic) } \\
\left(\mathrm{sec}^{-1}\right)\end{array}$ & $\begin{array}{c}k_{2(\text { (rev.mic) }} \times 10^{4} \\
\left(\mathrm{dm}^{3} \cdot \mathrm{mol}^{-1} \cdot \mathrm{sec}^{-1}\right)\end{array}$ \\
\hline 1.00 & 0.386 & 2.08 & - & - \\
2.77 & 0.690 & 3.72 & 5.16 & 10.0 \\
3.33 & 1.33 & 7.18 & 6.24 & 10.1 \\
4.16 & 1.65 & 8.91 & 7.88 & 10.2 \\
\hline
\end{tabular}

$\left.\left.[\mathrm{Fe}(\mathrm{tpy}))_{2}\right]_{0^{2+}}=4.0 \times 10^{-5} \mathrm{~mol} . \mathrm{dm}^{-3} ;\left[\mathrm{H}^{+}\right]_{0}=18.5 \times 10^{-2} \mathrm{~mol}_{\mathrm{dm}} \mathrm{dm}^{-3} ; \mathrm{CTAB}\right]=0.1 \mathrm{~mol} \mathrm{dm}^{-3} ; \mathrm{T}=304 \pm 0.1 \mathrm{~K}$

Table 3. Effect of variation of $W$ and [CTAB].

\begin{tabular}{|c|c|c|c|c|c|}
\hline $\begin{array}{c}\text { CTAB } \\
\left(\text { mol.dm-3 }^{-3}\right)\end{array}$ & $W$ & $\begin{array}{c}{[\mathrm{Br}]_{\mathrm{e}}=[\mathrm{CTAB}]^{*} 10 / \mathrm{Vol}} \\
\text { of aqueous layer }\end{array}$ & {$\left[\mathrm{H}^{+}\right]_{\mathrm{e}}$} & $\begin{array}{l}k^{\prime} \times 10^{3} \\
\left(\mathrm{sec}^{-1}\right)\end{array}$ & $\begin{array}{c}k_{2}=k^{\prime} /\left[\mathrm{H}^{+}\right]_{\mathrm{e}} \\
k_{2} \times 10^{4} \\
\left(\mathrm{~mol} \cdot \mathrm{dm}^{-3} \cdot \mathrm{sec}^{-1}\right)\end{array}$ \\
\hline \multirow[t]{6}{*}{0.05} & 4.44 & 12.5 & 5.80 & 2.89 & 4.98 \\
\hline & 6.66 & 8.33 & 3.86 & 2.67 & 6.91 \\
\hline & 8.88 & 6.25 & 2.90 & 2.56 & 8.82 \\
\hline & 13.3 & 4.16 & 1.93 & 1.96 & 10.1 \\
\hline & 16.6 & 3.33 & 1.54 & 1.56 & 10.1 \\
\hline & 20.0 & 2.77 & 1.28 & 1.32 & 10.3 \\
\hline \multirow[t]{8}{*}{0.1} & 2.22 & 25.0 & 5.8 & 2.20 & 3.81 \\
\hline & 3.33 & 16.6 & 3.86 & 1.51 & 3.92 \\
\hline & 4.44 & 12.5 & 2.9 & 1.35 & 4.68 \\
\hline & 6.66 & 8.33 & 1.93 & 1.29 & 6.69 \\
\hline & 8.88 & 6.25 & 1.54 & 1.27 & 8.82 \\
\hline & 13.3 & 4.16 & 0.966 & 0.95 & 10.4 \\
\hline & 16.6 & 3.33 & 0.773 & 0.81 & 10.3 \\
\hline & 20.0 & 2.77 & 0.64 & 0.66 & 10.3 \\
\hline \multirow[t]{8}{*}{0.2} & 2.22 & 25.0 & 2.9 & 1.11 & 3.82 \\
\hline & 3.33 & 16.6 & 1.93 & 0.753 & 3.90 \\
\hline & 4.44 & 12.5 & 1.54 & 0.693 & 4.77 \\
\hline & 6.66 & 8.33 & 0.966 & 0.634 & 6.66 \\
\hline & 8.88 & 6.25 & 0.773 & 0.647 & 8.92 \\
\hline & 13.3 & 4.16 & 0.483 & 0.491 & 10.2 \\
\hline & 16.6 & 3.33 & 0.386 & 0.398 & 10.1 \\
\hline & 20.0 & 2.77 & 0.322 & 0.330 & 10.3 \\
\hline
\end{tabular}

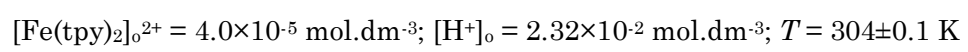

Table 4. Activation parameters.

\begin{tabular}{lcccc}
\hline \multicolumn{1}{c}{$W$} & $\begin{array}{c}E_{\mathrm{a}} \\
\left(\mathrm{kJ} . \mathrm{mol}^{-1}\right)\end{array}$ & $\begin{array}{c}\Delta H^{\#} \\
\left(\mathrm{~kJ} . \mathrm{mol}^{-1}\right)\end{array}$ & $\begin{array}{c}\Delta S^{\#} \\
\left(\mathrm{~J}^{*} \mathrm{~mol}^{-1} \cdot \mathrm{K}^{-1}\right)\end{array}$ & $\begin{array}{c}\Delta G^{\#} \\
\left(\mathrm{~kJ} . \mathrm{mol}^{-1}\right)\end{array}$ \\
\hline 4.44 & 38.5 & 36.0 & -175.1 & 85.3 \\
16.6 & 32.2 & 29.6 & -180.2 & 84.1 \\
Aqueous medium & 29.5 & 26.9 & -186.2 & 83.2 \\
\hline
\end{tabular}


actant concentration, the pseudo first order rate constant is around eight times more than in the presence of reverse micelles compared to aqueous medium at $\mu=4.16 \mathrm{~mol} . \mathrm{dm}^{-3}$ (Table 2). Also the pseudo first order rate constant decreases with increasing $W$. This can be explained as follows:

As these reactants are ionic, cannot stay in either the oil phase or the interface of reverse micelles; rather they prefer to stay inside the water pools. Therefore, the local concentration of the reactants in the water pools is much higher than in the bulk aqueous medium. As a result, the first order rate constant of the reaction is higher in the reverse micelles as compared to in the aqueous medium for a similar concentration of reactants. But with increasing $W$ value, the local concentration of the reactants decreases, reducing the rate of the reaction.

The second order rate constant which is obtained by dividing the first order rate constant with effective concentration of acid, is around ten times less than that in the presence of reverse micelles compared to aqueous medium at $\mu=4.16 \mathrm{~mol} \cdot \mathrm{dm}^{-3}$ (Table 2). The inhibition of the reaction in reverse micelles is due to low dielectric constant of the water pool compared to aqueous medium. Under these low dielectric constant conditions, the transition state which is more polar is stabilized by a polar solvent, i.e. water. Hence the reaction is slowed down in the presence of CTAB reverse micelles. Based on the observed results, the following mechanism is proposed for the dissociation of the complex in the presence of acid.

\subsection{Effect of $W$ and [CTAB] on Rate}

The rate data obtained at different values of $W$ at different CTAB concentrations given in Table 3 show that the second order rate constant increases slightly with increasing $W$ up to $W=8.88$ and thereafter remains constant. At constant CTAB concentration, increase in $W$ results in increase in dielectric constant and decrease in ionic strength. These two have opposing effect on the reaction. If there is only the effect of ionic strength, then the reaction rate should decrease with $W$. If the dielectric constant effect alone exists, there should be an increase in rate with increase in $W$. But the observed trend in the rate constants is a resultant effect of these two factors, resulting in a small increase in $k_{2}$. After $W=8.88$ there is no change in rate constants. This is due to the attenuation of special properties which approach that of bulk water. At constant $W$, there is no appreciable change in the second order rate constant with increasing CTAB. This shows that the reaction does not take place on the micellar interface but takes place entirely in the water pool. This can be expected since both the reactants $\mathrm{H}^{+}$and $\left\{\mathrm{Fe}(\text { tpy })_{2}\right\}^{2+}$ exists only in the water pool. Both are highly hydrophilic species and there are no electrostatic attractions between positive micellar surface and positively charged reactants.

In addition, the activation parameters $\left(E_{\mathrm{a}}\right.$, $\Delta H^{\#}$ and $\left.\Delta S^{\#}\right)$ of the reaction in an aqueous medium as well as in CTAB reverse micellar medium were determined from Arrhenius equation $\left(\log k^{\prime}=\log A-E_{\mathrm{a}} / 2.303 R T\right)$ and Eyring equation $\quad\left(k^{\prime}=\left(k_{\mathrm{B}} T / h\right)\right.$. exp $\left(-\Delta H^{\#} / R T\right)$. $\exp \left(\Delta S^{\# / R T}\right)$ ). The higher value of the activation energy $\left(E_{\text {a }}\right)$ in CTAB reverse micellar medium compared to that in an aqueous medium also supports the fact that the reaction in CTAB reverse micellar medium (Table 4) is inhibited.

\section{Conclusions}

The reaction between $\left[\mathrm{Fe}(\text { tpy })_{2}\right]^{2+}$ and $\left[\mathrm{H}^{+}\right]$ obeys first order kinetics with respect to each of the reactants in the CTAB reverse micellar medium. The reaction has been found to be inhibited around ten times in the presence of CTAB reverse micelles. Significant decrease of reaction rate in the $\mathrm{CTAB}$ reverse micellar medium is due low micro polarity of bound water present in the water pools. The slight increase in second order rate constants $\left(k_{2}\right)$ with the value of $W$ is a resultant effect of two factors, ionic strength and low dielectric constant of the water pools. The second order rate constant $\left(k_{2}\right)$ of the reaction is almost constant at all concentrations of $\mathrm{CTAB}$, indicating that the reaction completely takes place in the water pool.

\section{Acknowledgements}

KVNL and PS thank UGC, India under the minor research project MRP-4552(14) (SERO/UGC) and DST, India under the project SERB/F/5725/2013-14 respectively for financial support. KVNL is also thankful to the management of Gayatri Vidya Parishad College of Engineering, Visakhapatnam for their support and encouragement. 


\section{References}

[1] Lubica, K, Eva, M., Peter, S., Petr, S., Petr, K. (2015). Nature of CTAB/Water/Chloroform Reverse Micelles at Above- and Subzero Temperatures Studied by NMR and Molecular Dynamics Simulations. Langmuir, 31(30), 8284 - 8293. DOI: 10.1021/acs.langmuir.5b01776.

[2] Amanda, J.M., John, W., Melanie, M.B. (2014). NMR and molecular dynamics study of the size, shape, and composition of reverse micelles in a cetyltrimethylammonium bromide (CTAB)/n-hexane/pentanol/water microemulsion. J. Phy. Chem. B., 118(36), 10767-10775. DOI: 10.1021/jp504585k

[3] Michael, R., Branka, M.L, Nancy, E.L., Kenneth, W.H. (2004). Water motion in reverse micelles studied by quasielastic neutron scattering and molecular dynamics simulations. J. Chem. Phys., 121(16), 7855-7868. DOI: $10.1063 / 1.1792592$.

[4] Menger, F.M., Donohue, J.A., Williams, R.F. (1973). Catalysis in water pools. J. Am. Chem. Soc., $95(1), \quad 286-288$. DOI: 10.1021/ja00782a075.

[5] Fendler, J.H. (1976). Interactions and reactions in reverse micellar media. Acc. Chem. Res., 9(4), 153-161. D O : 10.1021/ar50100a005

[6] Mishra, B.K., Valandikar, B.S., Knujappu, J.J., Manomar, C. (1989). Influence of microemulsion structure on reaction rates. J. Colloid Interface Sci., 127, 373-376. DOI: 10.1016/0021-9797(89)90043-X

[7] Sunamoto, J., Hamada, T. (1978). Solvochromism and Thermochromism of Cobalt (II) Complexes Solubilized in Reversed Micelles. Bull. Chem. Soc. Jpn., 51, 3130-3135. DOI: $10.1246 /$ bcsj. 51 .

[8] Mario, J.P, Chaimovich, H. (1986). Water activity in reversed sodium bis(2-ethylhexyl) sulfosuccinate micelles. J. Phys. Chem., 90(2), 282-287. DOI: 10.1021/j100274a016.

[9] Yang, L., Zhao, K. (2007). Dielectric model and theoretical analysis of cationic reverse micellar solutions in $\mathrm{CTAB} /$ isooctane/nhexanol/water systems. Langmuir, 23, 8732-8739. DOI: 10.1021/la700665s.

[10] Pileni, M.P., (1993). Reverse micelles as micro reactors. J. Phys. Chem., 7, 6967-6973. DOI: 10.1021/j100129a008.

[11] Irfan, H.L., Nagi, R.E.R., Jeenat, A., Arifa, A. (2019). Concept of Reverse Micelle Method For the Synthesis of Nano-Structured Materials. Current Nano Science, 15(2), 129-136. DOI: $10.2174 / 1573413714666180611075115$
[12] Hoorshad, F., James, P.K., Victor R.V., Olivia, A.G. (2012). Ionic Concentration Effects on Reverse Micelle Size and Stability: Implications for the Synthesis of Nanoparticles. Langmuir, 25, 9267-9274.

[13] Arash, H.K., Rashidi, A.M., Kashi, G. (2017). Synthesis of tungsten nanoparticles by reverse micelle method. Journal of Molecular Liquids, 241, 897-903. DOI: 10.1016/j.molliq.2017.06.053.

[14] Garcia-Rio, L., Ramon Leis, J., Elena, P., Emilia, I. (1993). Transfer of the nitroso group in water/AOT/isooctane micro emulsions: intrinsic and apparent reactivity. $J$. Phys. Chem., 97(13), 3437-3442. DOI: $10.1021 / \mathrm{j} 100115 \mathrm{a} 057$.

[15] Johnson, M.D., Lorenz, B.B., Wilkins, P.C., Lemons, B.G., Baruah, B., Lamborn, N., Stahla, M., Chatterjee, P.B., Richens, D.T., Crans, D.C. (2012). Switching Off Electron Transfer Reactions in Confined Media: Reduction of $\left[\mathrm{Co}(\text { dipic) })_{2}\right]^{-}$and $[\mathrm{Co}(\text { edta })]^{-}$by Hexacyanoferrate(II). Inorg. Chem., 51(5), 2757-2765. DOI: 10.1021/ic201247v.

[16] Shyamala, P., Subba Rao, P.V. (2010). Kinetics of Oxidation of Iodide by Vanadium (V): Catalysis by the Water Pools of CTAB Reverse Micelles. Kinet. Catal., 51(2), 207-210. DOI: $10.1134 / \mathrm{S} 0023158410020060$

[17] Jamil, K.J.S. (2006). Kinetics of the Oxidation of Phenyl hydrazine by $[\mathrm{Fe}(\mathrm{CN}) 6]^{3-}$ in Water-in-Oil Microemulsion. J. Dispersion. Sci. Technol., 27(6), 795-798. DOI: $10.1080 / 01932690500482129$.

[18] Chuanyi, Y., Shaokun, T., He, Z., Deng, X. (2005). Kinetics of lipase-catalyzed hydrolysis of olive oil in AOT/isooctane/reverse micelles. Journal of Molecular Catalysis B: Enzymatic, 35 ( 4 ), $\quad 108-112$. D O I : 10.1016/j.molcatb.2005.06.005

[19] Miyake, Y., Owari, T., Ishiga, F., Teramoto, M. (1994). Enzymatic reaction in water-in-oil microemulsions - Rate of hydrolysis of a hydrophobic substrate, 2-naphthyl acetate. J. Chem. Soc. Faraday Trans., 90, 979-986. DOI: 10.1039/FT9949000979

[20] García-Río, L., Mejuto, J.C., P'rez-Lorenzo, M. (2005). Microheterogeneous Solvation for Aminolysis Reactions in AOT-Based Water-in-Oil Microemulsions. Chemistry A Europian Journal, 11, 4361-4373. DOI: 10.1002/chem.200401067.

[21] Shyamala, P., Subba Rao, P.V., Ramakrishna, K. (2000). Kinetics of dissociation of tris (2,2'-bipyridyl) iron (II) in the water pools of CTAB reverse micelles. Ind. J. Chem. 39A, 643-645. 
[22] Nagalakshmi, K.V., Padma, M., Srikanth, V., Shyamala, P., Subba Rao, P.V. (2013). Catalytic effect of CTAB reverse micelles on the kinetics of dissociation of bis(2,4,6-tripyridyl-striazine) iron(II). Transition Met. Chem., 38, 523-527. DOI: 10.1007/s11243-013-9719-3.

[23] Deepa, S., Khilar, K.C., Gousia, B., Subba Rao, P.V. (2005). Kinetics of basic hydrolysis of tris (1,10-phenanthroline) iron(11) in Triton X 100/hexanol/water reverse micelles in cyclohexane. Colloids and Surfaces A: Physicochemical and Engineering Aspects, 268(1-3), 73-77. DOI:10.1016/j.colsurfa.2005.05.062.
[24] Nagalakshmi, K.V., Shyamala, P. (2019). Kinetics of oxidation of $\left[\mathrm{Fe}(\text { phen })_{3}\right]^{+2}$ by persulphate: catalysis in the water pools of CTAB reverse micelles. Bulg. Chem. Comm., 51(4), 494-498. DOI: 10.34049/bcc.51.4.4946.

[25] Luisi, P.L., Straub, B.E. (1984). Reverse Micelles, Plenum Press, New York, P.73, DOI: 10.1002/pol.1985.130230312

[26] Munoz, E., Gomez-Herrera, C., Garciani, M., Moya, M.L., Sanchez, F. (1991). Kinetics of the oxidation of iodide by persulphate in AOT-oil-water, Microemulsions. J. Chem. Soc. Faraday Trans, 87(1), 129-132. DOI: 10.1039/FT9918700129. 